PLPB: Pendidikan Lingkungan dan Pembangunan Berkelanjutan

DOI: https://doi.org/10.21009/PLPB.181.02

DOI: 10.21009/PLPB

\title{
STRATEGIC PLANNING AT PT AETRA AIR JAKARTA IN DRINKING WATER MANAGEMENT.
}

\author{
Zulfa Hananiawati \\ Konsultan Kementerian Pekerjaan Umum dan Perumahan Rakyat \\ zulfa_hanania@yahoo.com
}

\begin{abstract}
The aim of this research is to determine how the strategy planning and the implementation in drinking water management by PT Aetra to deal with the universal access and based on Permen PU no. 18/PRT/M/2007. Analysis used descriptive qualitative with comparative approach between strategic planning and theory of strategic planning and management. As a commitment in the drinking water service excellence, strategic planning and management set out in the annual work meeting and resulted in business strategies implemented next year. Strategy planning which is formulated in the policies and regulations form in order to achieve the vision, mission and values. Strategic planning has not been considered environmental factors such as seasonal changes which are very influential in the water management of drinking water. The total of the precipitation influence in water management by Aetra especially in the quality of raw water instead of the quantity of raw water. In managing water, the concept of sustainable development has been applied and continues to be improving needed for a balance between profit, environmental and social.
\end{abstract}

Keywords: strategy planning, strategy management, the management of drinking water.

\begin{tabular}{|l|l|l|l|}
\hline Volume XVIII & Nomor 01 & Maret 2017 & ISSN 1411-1829 \\
\hline
\end{tabular}




\section{Pendahuluan}

Proses penyediaan air oleh perusahaan penyedia air minum swasta atau milik pemerintah seperti Perusahaan Daerah Air Minum (PDAM) sangat tergantung pada kondisi dan permasalahan sumber air baku yang tersedia. Manusia cenderung memanfaatkan air secara berlebihan dan tidak mempertimbangkan kelestarian maupun keberlanjutannya, sehingga membuat kondisi sumber air baku semakin menurun, terutama yang berasal dari air permukaan seperti sungai.

PT Aetra Air Jakarta bertugas menyediakan air bersih terhadap masyarakat Daerah Khusus Ibukota (DKI) Jakarta. PT Aetra bertanggung jawab untuk mengelola, mengoperasikan, memelihara, serta melakukan investasi untuk mengoptimalkan, menambah dan meningkatkan pelayanan air bersih.

Wilayah operasionalnya adalah sebelah timur sungai Ciliwung meliputi sebagian wilayah Jakarta Utara, sebagian wilayah Jakarta Pusat, dan seluruh wilayah Jakarta Timur dengan cakupan pelayan $59,92 \%$.

Strategi perencanaan dan manajmen PT. Aetra bukan hanya aspek teknis, namun juga dari aspek non teknis (program, anggaran, dan prosedur), termasuk sumberdaya manusia, (karyawan), karena keterkaitannya yang tidak dapat dipisahkan. Bentuk perencanaan dan pengelolaan yang dibuat oleh manajemen PT Aetra harus dirancang berlandaskan strategi pembangunan yang berkelanjutan. Konsep tersebut dikenal dengan sustainable development. atau pembangunan berwawasan lingkungan yang mempertimbangkan beberapa aspek sosial, ekonomi, dan "environmental goals".

Berdasarkan uraian tersebut, maka diadakan penelitian Strategic Planning PT Aetra Air Jakarta dalam Pengelolaan Air Minum: Studi Deskriptif Teoretik Tahun 2016. Rumusan masalah dalam penelitian ini adalah bagaimana implementasi strategi perencanaan (Strategy Planning) PT. Aetra Air Jakarta dalam pengelolaan air minum?

\section{Metodologi Penelitian}

Tujuan penelitian ini adalah untuk mengetahui bagaimana strategic planning dan implementasinya di PT Aetra dalam pengelolaan air minum ke masyarakat untuk menghadapi universal access yang berpedoman pada Peraturan Menteri Pekerjaan Umum No. 18 tahun 2007.

Penelitian ini merupakan deskriptif teoretik. Analisis data bersifat deskriptif kualitatif. Kegiatan dalam penelitian ini yaitu mendeskripsikan kondisi di lapangan terkait strategic planning dalam pencapaian Sustainable Development Goals (SDGs) atau universal access tahun 2019 yang berpedoman pada Peraturan Pemerintah tentang Penyelenggaraan Pengembangan Sistem Penyediaan Air Minum (3K).

Penelitian dilakukan dengan metode komparatif, yakni dengan membandingkan antara teori dengan kenyataan di lapangan serta kemudian diambil kesimpulan bagaimana strategy planning diimplementasikan. Analisis juga dilakukan dengan menggunakan SWOT yang menghasilkan isu strategis dan

\begin{tabular}{|l|l|l|l|}
\hline Volume XVIII & Nomor 01 & Maret 2017 & ISSN 1411-1829 \\
\hline
\end{tabular}


menjadi dasar dalam penyusunan misi, penetapan tujuan, pengembangan strategi, dan penetapan kebijakan perusahaan. Adapun kerangka penelitian strategy planning pengelolaan air minum PT Aetra dapat dilihat pada gambar 1 .

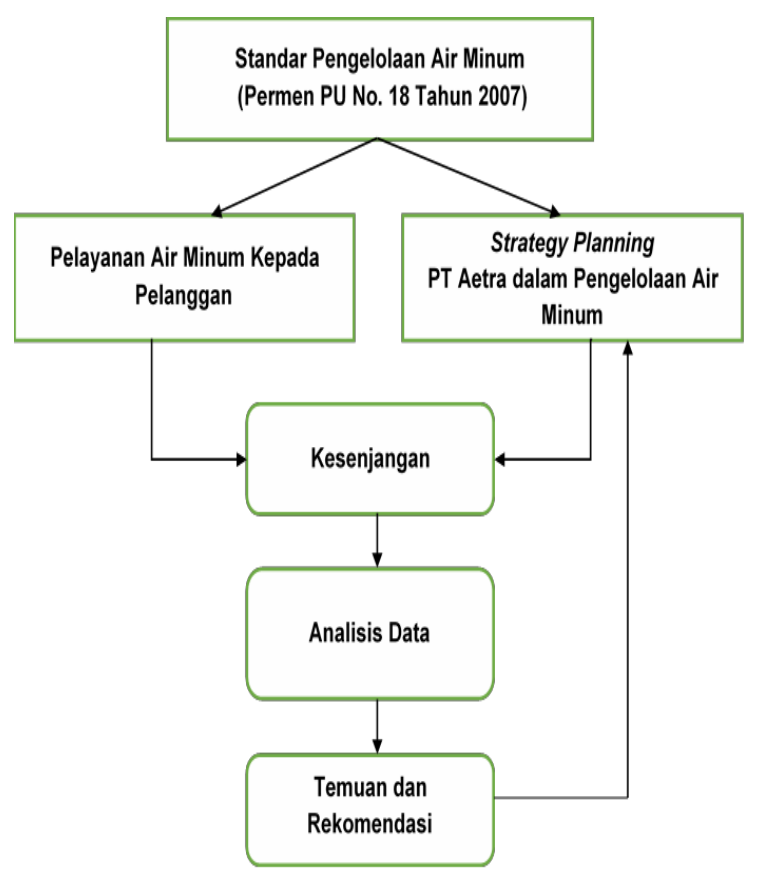

Gambar 1.

Strategy Planning Pengelolaan Air Minum PT Aetra

\section{Hasil Penelitian Dan Pembahasan}

PT Aetra sebagai perusahaan yang bergerak dalam usaha pengelolaan dan perencanaan (Strategy Planning and Management) air minum kepada masyarakat, tentu saja sangat membutuhkan air baku yang memiliki kualitas sesuai standar. Konsep sustainable development menjadi dasar dalam penetapan strategy planning and management. Hal ini bertujuan agar terjadi keseimbangan terhadap aspek lingkungan, sosial dan ekonomi. Dengan kata lain menyeimbangkan antara usaha mendapatkan profit dari pengembangan pelayanan air minum dengan konservasi lingkungan dan tidak mengorbankan kebutuhan sosial masyarakat.

PT Aetra peduli terhadap usaha konservasi air dan lingkungan. Usaha konservasi yang bersinergi dengan berbagai pihak dilakukan seperti melakukan penanaman pohon di bagian hulu (Lembang) maupun yang berada di hilir (Jakarta).

Hasil wawancara kepuasan pelayanan air minum sebanyak lebih dari $75 \%$ pelanggan tidak pernah menerima air yang berwana. Hanya $25 \%$ warga yang saat musim hujan kadang-kadang menerima air yang sedikit kecoklatan akibat lumpur. Warna yang muncul pada air tidak dipermasalahkan oleh pelanggan, karena sangat jarang terjadi. Warga beranggapan sedang terjadi pengurasan reservoir atau pekerjaan perbaikan pipa.

Kuantitas air yang diterima pelanggan menjadi salah satu kriteria pelayanan air. Sebanyak $90 \%$ pelanggan merasa cukup dengan kuantitas air yang diterima. Sebanyak $10 \%$ pelanggan menjawab lainnnya, karena di daerah tersebut baru satu bulan dilakukan penggantian pipa, sehingga dalam bulan tersebut air mencukupi.

Kontinuitas pelayanan air sesuai Peraturan Pemerintah Pekerjaan Umum No 18 Tahun 2007, air harus mengalir selama 24 jam perhari. Pelayanan air Aetra telah memenuhi standar persyaratan sesuai peraturan yang ditetapkan dengan $100 \%$ pelanggan menjawab air selalu mengalir

\begin{tabular}{|l|l|l|l|}
\hline Volume XVIII & Nomor 01 & Maret 2017 & ISSN 1411-1829 \\
\hline
\end{tabular}


dari kran kapan pun kran dibuka.

$$
\text { Pada tahun 2011, PT Aetra }
$$
segudang masalah yang harus segera diselesaikan. Permasalahan mendesak yaitu melunasi hutang kepada PAM Jaya sejak 1998 hingga 2012, pencabutan subsidi dari PAM Jaya mulai 2011, anggapan bahwa harga air PT Aetra mahal, air tidak layak minum dan kehilangan air. Semua permasalahan itu muncul karena strategi bisnis dan kinerja karyawan sehingga membuat perusahaan bekerja tidak efisien dan efektif.

Perombakan strategi bisnis dengan mengubah orientasi bisnis tanpa mengandalkan subsidi PAM Jaya dilakukan. Dengan demikian, untuk terlepas dari kebiasaan menerima subsidi dan berdiri dengan usaha sendiri perlu dilakukan peningkatan kemampuan sumberdaya manusia (SDM)/soft skill dan juga pelatihan. Peningkatan kapasitas demi mengembangkan.

SDM salah satunya diberikan dengan pembekalan nilai-nilai karakter kepribadian dan penumbuhan empati. Selain itu pembenahan sistem perekrutan juga dilakukan agar terjadi keselarasan ritme budaya kerja karyawan yang berasal dari berbagai latar belakang dan menjadi tantangan yang harus dihadapi demi mencapai tujuan yang sama.

Komitmen PT Aetra dalam pelayanan air minum yaitu selalu menetapkan strategi perencanaan dan pengelolaan air minum dalam rapat kerja tahunan. Rapat kerja tahunan akan menghasilan perencanaan bisnis tahun berikutnya. Dalam rapat kerja tersebut, penetapan perencanaan ke depan selalu berdasarkan visi, misi dan nilai-nilai perusahaan. Perencanaan juga berdasarkan pada kebijakan dan peraturan yang ada serta hasil evaluasi selama tahun berjalan dan tahun sebelumnya.

Evaluasi tahunan dilakukan oleh komite audit baik internal PT Aetra maupun bekerjasama dengan auditor eksternal demi profesionalisme kinerja PT Aetra secara keseluruhan maupun secara khusus di masing-masing departemen. Temuan yang muncul pada akhirnya akan ditindaklanjuti baik temuan dari auditor internal dan auditor eksternal. Environmental planning dan management (perencanaan dan pengelolaan lingkungan) merupakan tantangan strategis.

Perusahaan yang sukses bukan hanya diukur dari seberapa banyak keuntungan yang didapat dari produk yang dihasilkan, namun juga kepedulian terhadap perlindungan lingkungan alam. Perencanaan dan pengelolaan lingkungan adalah bagian dari visi, misi, dan strategi yang secara efektif perlu direncanakan sebagai keunggulan kompetitif. Pentingnya perencanaan dan pengelolaan yang efektif dalam environmental management systems adalah dalam rangka memanfaatkan nilai-nilai yang akan diperoleh perusahaan yang mengadopsi environmental strategies.

Proses penerapan strategi pada sebuah perusahaan harus dapat menetapkan tujuan, membuat kebijakan, memotivasi karyawan, dan mengalokasikan sumberdaya sehingga strategi yang telah dirumuskan dapat dilaksanakan. Penerapan strategi akan mencakup pengembangan budaya yang mendukung pada strategi tersebut, penciptaan struktur organisasional yang efektif, pengerahan ulang upaya pemasaran, penyiapan anggaran, pengembangan sistem informasi, dan

\begin{tabular}{|l|l|l|l|}
\hline Volume XVIII & Nomor 01 & Maret 2017 & ISSN 1411-1829 \\
\hline
\end{tabular}


adanya pengaitan kompensasi karyawan dengan kinerja karyawan.

Tahapan strategy planning yang paling penting yaitu environmental scanning dimana dari berbagai informasi internal dan eksternal yang berhasil dikumpulkan akan dilakukan analisis SWOT. SWOT digunakan sebagai suatu perangkat yang sangat umum digunakan untuk membuat keputusan dan menetapkan strategi bisnis pada tahun berikutnya. Hasil analisis SWOT pada akhirnya akan berguna dalam memaksimalkan kekuatan yang ada demi meminimalkan kelemahan, dan mengoptimalkan kesempatan yang dimiliki demi menghilangkan ancaman yang akan dihadapi.

Isu strategis yang berhasil dirumuskan merupakan hasil analisis faktor-faktor baik internal maupun eksternal (SWOT) yang dapat dirumuskan sebagai berikut:

1. Regulasi pemerintah DKI Jakarta terkait pengelolaan dan pengendalian penggunaan air tanah belum efektif.

2. Keterpaduan dan koordinasi program antar stakeholder (pemerintah dan swasta) belum efisien.

3. Infrastruktur terbangun belum optimal dalam pengembangan pelayanan airminum.

4. Sistem database pelanggan yang tidakakurat.

5. Harga air mahal dan tidak layak minum.

Strategy Formulation merupakan bentuk pengembangan rencana jangka panjang untuk mencapai efektivitas dari berbagai peluang yang ada dan menghindari ancaman lingkungan eksternal yang dapat mempengaruhi kinerja perusahaan. Rumusan strategi yang ditetapkan untuk mencapai visi perusahaan yaitu "Penyedia Layanan Air Minum Terdepan di Indonesia" dalam bentuk misi, tujuan perusahaan, startegi dan berbagai kebijakan yangdibuatbaikdi internal dan eksternal perusahaan. Bentuk strategy implementation dari ketetapan yang telah disepakati bersama dalam rapat tahunan diwujudkan melalui pengembangan program, anggaran, dan prosedur. Proses tersebut meliputi perubahan budaya secara menyeluruh, struktur dan atau sistem manajemen dari organisasi secara keseluruhan.

Keputusan strategis bersama yang ditetapkan PT Aetra dalam rapat tahunan sangat memberikan dampak pada perkembangan perusahaan kedepan. Oleh karena itu, evaluasi dan proses kontrol dalam perusahaan terhadap hasil implementasi keputusan yang dibuat menjadi suatu keharusan. Evaluasi dan kontrol dilakukan dengan membandingkan antara rencana yang telah ditetapkan dengan kinerja yang dihasilkan.

Kinerja pada dasarnya merupakan hasil akhir dari aktivitas yang telah dilaksanakan dalam tahapan perencanaan strategi. Usaha peningkatan (act) merupakan tahapan terakhir dalam sebuah strategy planning agar dalam setiap usaha perencanaan dan pengelolaan lingkungan dalam perusahaan selalu diikuti dengan usaha peningkatan dari capaian target yang telah dihasilkan.Usaha perbaikan dan peningkatan yang dilakukan pada unit IPA merupakan faktor penting yang harus diperhatikan oleh para manager. Unit IPA

\begin{tabular}{|l|l|l|l|}
\hline Volume XVIII & Nomor 01 & Maret 2017 & ISSN 1411-1829 \\
\hline
\end{tabular}


merupakan ujung tombak dari usaha pengembangan pelayanan air minum. Usaha peningkatan dibutuhkan seperti dalam hal pemanfaatan unit pengolah lumpur (decanter) yang merupakan teknologi ramah lingkungan sehingga lumpur yang dibuang tidak mencemari lingkungan sekitar.

Program monitoring juga dibuat PT Aetra untuk mencari informasi apakah dalam usaha pengolahan air minum mencemari lingkungan atau tidak. Program monitoring yang dilakukan diimbangi dengan adanya perbaikan dan peningkatan teknologi baru dan update ketersediaan informasi baru sehingga usaha pengurangan beban limbah yang dihasilkan dapat tercapai. Pada akhirnya lingkungan dapat terjaga kelestariannya untuk generasi yang akan datang dan konsep sustainable development menjadi landasan perusahaan dalam menetapkan strategy planning.

PT Aetra sebagai perusahaan besar telah memahami dan mengikuti tahapan-tahapan sesuai teori strategi manajemen. Dampak terhadap lingkungan dan sosial masyarakat juga ikut diperhatikan dengan mengadakan berbagai kegiatan dalam rangka konservasi terhadap lingkungan dan air. Konsep seperti ini sesuai dengan konsep pembangunan berkelanjutan.

Pembangunan berkelanjutan tidak dapat dicapai tanpa manufaktur yang berkelanjutan. Manufaktur yang berkelanjutan adalah salah satu proses atau strategi untuk mencapai tujuan pembangunan berkelanjutan. Produksi berkesinambungan membutuhkan seluruh organisasi menjadi sadar lingkungan, memerlukan dukungan penuh dan partisipasi dari setiap bagian perusahaan yang kesemuanya akan menjadi investasi masa depan.
PT Aetra sebagai suatu perusahaan yang memperhatikan faktor dan dampak lingkungan seperti perubahan musim, maka PT Aetra seharusnya juga dapat memasukkan perubahan musim sebagai bahan kajian untuk penentuan besar biaya pengelolaan air. Pengelolaan air yang dilakukan oleh PT Aetra sangat bergantung pada kualitas air baku, bukan pada kuantitas dan kotinuitas air baku yang mengalir di Kalimalang. Berikut skema unit pengolahan pada instalasi pengolahan air (IPA) Buaran.

Hasil perhitungan dengan menggunakan metode substitusi dan eliminasi didapatkan biaya pengolahan air pada bulan kering sebesar Rp.3.002.816,75,- dan biaya pengolahan pada bulan basah sebesar Rp.1.381.316,75,-. Dengan informasi berapa banyak bulan kering dan bulan basah maka dapat disimpulkan bahwa banyaknya bulan kering membuat biaya pengolahan semakin besar.

Besar biaya produksi air berdasarkan kecenderungan banyak bulan kering pada tahun 2017 adalah Rp.15.014.083, 75,-. Besar biaya produksi air berdasarkan kecenderungan banyak bulan basah pada tahun 2017 adalah Rp.9.669.217, 25,-. Total biaya yang akan dikeluarkan untuk melakukan pengolahan air pada tahun 2017 adalah Rp.24.683.301,-.

\section{Kesimpulan}

PT Aetra dalam memenuhi visi dan misi perusahaan selalu berpedoman pada konsep sustainable development yang memiliki keseimbangan antara keuntungan yang didapat (profit oriented), sosial, dan lingkungan. Untuk itu ditekankan pada setiap karyawan dari berbagai level

\begin{tabular}{|l|l|l|l|}
\hline Volume XVIII & Nomor 01 & Maret 2017 & ISSN 1411-1829 \\
\hline
\end{tabular}


konsisten menaati standar kerja yang berlaku, dengan menetapkan strategy planning and management dalam pengelolaan air minum.

Proses pengembangan konsep sustainable development di PT Aetra dilakukan dengan melibatkan restrukturisasi dan perubahan budaya, sehingga kinerja lebih efektif dan efisien. Dengan peningkatan kinerja PT Aetra berdasarkan sustainable development, maka akan dirasakan juga oleh masyarakat dalam memenuhi kebutuhan air minum.

\section{Daftar Pustaka}

Aetra Air Jakarta. "Profil Perusahaan", Aetra Air Jakarta Online. http://www.aetra.co.id/profil_perusahaa n.html (diakses 7 September 2016).

Kontan.'Menyelaraskan Ritme dari Dua Budaya Kerja", Kontan Online.http://executive.kontan.co.id/ne ws/menyelaraskan-ritme-dari-duabudaya-kerja.html (diakses 23 Desember 2016)

Madu, Christian N. Environmental Planning and Management. London: Imperial College Press, 2007.

Putrawan, I Made. Konsep-Konsep Dasar Ekologi Dalam Berbagai Aktivitas Lingkungan. Bandung: Alfabeta, 2014.

Sinar harapan. "Mohamad Selim Visioner",Sinarharapan

Online.http://sinarharapan.co/news/rea
d/140506036/Mohamad-SelimVisioner.html (diakses 23 Desember 2016. 
